\title{
Assessment of Exposure to Sexually Explicit Materials and Substance Abuse among High-School Adolescents in North Shewa Zone: Application of Logistic Regression Analysis
}

\author{
Berhanu Teshome Woldeamanuel $(D$, Leul Mekonnen Anteneh, \\ Yordanos Berihun Yohannes, and Merga Abdissa Aga (iD \\ Department of Statistics, College of Natural and Computational Sciences, Salale University, Fitche, Ethiopia \\ Correspondence should be addressed to Berhanu Teshome Woldeamanuel; berteshome19@gmail.com
}

Received 26 August 2019; Accepted 27 February 2020; Published 11 May 2020

Academic Editor: Brian Conway

Copyright (C) 2020 Berhanu Teshome Woldeamanuel et al. This is an open access article distributed under the Creative Commons Attribution License, which permits unrestricted use, distribution, and reproduction in any medium, provided the original work is properly cited.

\begin{abstract}
Background. The use of substances such as cigarettes, khat, alcohol, and other illicit drugs like hashish, heroine, cannabis, and cocaine is a global major public threat, which affects young adult people particularly in developing countries. This study aims to assess the risk factors associated with substance use and exposure to sexually explicit materials among high-school adolescents in north Shewa zone, Oromia region. Method. A cross-sectional study was conducted to assess substance use and exposure to sexually explicit materials among high-school adolescents in North Shewa zone, Oromiya, Ethiopia, using a structured selfadministered questionnaire adapted from the 2008 "Community That Care Youth Survey" for adolescent substance use and problem behaviors. The study used descriptive statistics and logistic regression analysis to identify the significant factors associated with substance use and exposure to sexually explicit materials among high school adolescents in the study area. Result. The prevalence of lifetime and current substance use was $47.7 \%$ (95\% CI: $0.427,0.527)$ and $30.4 \%$ (95\% CI: $0.258,0.350$ ), respectively. $17.8 \%$ use khat in their life and $16.6 \%$ used khat in the past 30 days; $42.2 \%$ ever used alcohol and $26.1 \%$ currently uses alcohol; $4.8 \%$ and $4.5 \%$ used cigarette in lifetime and in the past 30 days, while $16.4 \%$ use other illicit drugs in lifetime and $8.4 \%$ use illicit drugs in the past 30 days, respectively. Distributions of substance use by sex indicate that male adolescents are more like likely $61.1 \%$ use substances than females. While, the prevalence of exposure to sexually explicit materials among high school adolescents was $35.8 \%$ (95\% CI: $0.310,0.406)$. Factors positively associated with increased substance use were being male (OR $=2.334,95 \%$ CI: 1.549 , 9.926), living through high level of family conflict ( $\mathrm{OR}=6.25,95 \% \mathrm{CI}: 1.745,10.00)$, poor family management $\mathrm{OR}=27.084,95 \%$ CI: $1.624,45.56)$, peer pressure $(\mathrm{OR}=12.882,95 \% \mathrm{CI}: 1.882,88.153)$, poor academic performance $(\mathrm{OR}=14.48,95 \% \mathrm{CI}: 1.290$, 162.58), and low school commitment ( $\mathrm{OR}=11.951,95 \% \mathrm{CI}: 1.418,100.73)$. While, being male $(\mathrm{OR}=7.52,95 \% \mathrm{CI}: 2.611,21.739)$, age $14-16(\mathrm{OR}=0.201,95 \% \mathrm{CI}: 0.071,0.565)$, friends watch/read sexually explicit materials $(\mathrm{OR}=5.376,95 \% \mathrm{CI}: 1.010,28.571)$, and khat chewing $(\mathrm{OR}=12.5,95 \% \mathrm{CI}: 2.924,25.632)$ were factors significantly associated with high-school adolescents exposure to sexually explicit materials. Conclusion. The magnitude of prevalence for substance uses and exposure to sexually explicit materials in the study area was still higher. Therefore, interventions that focus on family management, peer pressure, and school commitment are required to decrease the prevalence of substance uses and exposure to sexually explicit materials among highschool adolescents.
\end{abstract}

\section{Introduction}

The use of substances such as cigarettes, khat, alcohol, and other illicit drugs like hashish, heroine, cannabis, and cocaine is a global major public threat, which affects young adult people particularly in developing countries [1-3]. Drug uses disorders and ill-health-related conditions are major public health problems. Worldwide, it is estimated that alcohol and illicit drugs accounted for $5.4 \%$ and $3.7 \%$ of the global burden of disease in 2009, respectively [4]. It is also 
estimated that $9 \%$ of the world population aged 12 or older are classified with dependence on psychoactive substances such as alcohol [5].

The United Nations in 2014 indicated globally, alcohol consumption accounts for about $5.9 \%$ or nearly 3.3 million deaths of the global deaths, and 5.1\% of the global burden of disease and injury were attributable to alcohol consumption in 2012 [6]. Early start of drinking increases the likelihood of alcohol-related injuries, motor vehicles crashes involvement, unprotected intercourse, and interpersonal violence. Alcohol uses also to contribute to youth suicides, homicides, and fatal injuries [7].

The most locally produced and highly consumed alcohols in Ethiopia are tella, areque (katikala), shamita, tej, and borde. Aside from locally fermented alcohols beers, gin, wine, and other alcoholic liquors are widely used alcohols products [8]. The Ethiopian public health association (EPHA) in 2007 reported that about $30.5 \%$ of adolescents aged 15-24 in Ethiopia ever used substances in their life, while young adults seem to be the most involved in alcohol and khat consumption than any other population group [9]. A similar study based on the 2005 behavioral surveillance surveys have reported that males are more likely to use substances than females, but the trends for the habits of using substances is rising from time to time among females [10]. The Ethiopian Demographic and Health Survey 2016 reported the prevalence of alcohol use among men and women is $46 \%$ and $35 \%$, respectively, and $27 \%$ of men and $12 \%$ of women ever chewed khat [11].

Previous studies showed that peer pressure, accessibility, cultural accessibility, parental involvement, and low self esteem are the major reasons for starting using substances in Ethiopia, while some adolescents use substances to relax, and to avoid or forget their problems and anxieties, like problems arising from economic stress [12].

A cross-sectional study conducted on substance uses and associated factors among Haramaya university students indicated that more than $62 \%$ of students use at least one substance, $50.2 \%$ use alcohol, $41 \%$ chewed khat in their lifetime, $23.6 \%$ currently use khat, while $22 \%$ were using cigarettes at least once in their lifetime, $10.8 \%$ currently smoke cigarette and 7.4\% used illicit drug like hashish [13]. A systematic review and meta-analysis on substance use among adolescents aged 10-19 years in sub-Saharan Africa between 2000 and 2016 revealed the prevalence of substance use ranged from $37 \%$ in South Africa to $55.5 \%$ in central Africa with the overall prevalence of substance use $41.6 \%$. About 32.8\% uses alcohol, 23.5\% uses cigarette, 22\% use khat, and $15.9 \%$ use cannabis [14].

Wakgari and Aklilu studied substance use and its predictors among undergraduate medical students of Addis Ababa University in Ethiopia, the study reported $22 \%$ of students used alcohol, $7 \%$ used khat, and $9 \%$ of students use cigarette [15]. A similar study conducted in Debre Birhan University reported $36.3 \%$ of the lifetime use of alcohol, $10.9 \%$ lifetime use of khat, and $7.4 \%$ lifetime use of cigarette among students, while $4.2 \%$ and $4.5 \%$ of students were used shisha and cannabis, respectively, in their lifetime. Further, the study reported 17\%, 5.7\%, and
$3.1 \%$ of students are currently using alcohol, khat, and cigarette, respectively [16]. Shimelis and Wosen in their study on causes, prevalence, and consequences of alcohol and drug abuse among Mekelle University students reported the prevalence of alcohol and drug abuse among students is $30 \%$ and the major reason for alcohol and drug abuse are peer pressure, psychological factors, academic factors, and social factors [17].

A study conducted in Nepal reported, 6\% prevalence of substance use among high-school adolescents [18]. A similar study in the Southeast Asian nations reported that the lifetime prevalence of illicit drug uses was 16.9\% [19].

Another study conducted in Gondar University showed $62.9 \%$ prevalence of drug uses and the major contributing factors of substance uses are relations, increase performance, and peer pressure [20]. While Gobeje et al. [21] in their studies about the prevalence of substance use and associated factors among preparatory students of Woldia Town, northeast Ethiopia, in 2015 found that the overall prevalence of substance use is $34.6 \%$, whereas $23.5 \%$ of students chewed khat and use cigarettes. A multidomain factor analysis studies conducted in Woreta Town found $47.9 \%$ prevalence of current substance uses and $65.4 \%$ prevalence of lifetime substance use among highschool adolescents in Woreta Town [22]. Similarly, a study done on prevalence of substance abuses among University students in Tigray, northern Ethiopia, reported $43.9 \%$ of university students abuse substances [23].

In Harar, eastern Ethiopia, Reda [24] found a $12.2 \%$ prevalence of cigarette smoking among school adolescents. While, the Drug Administration and Control Authority in 2005 found $10.1 \%-11.5 \%$ prevalence of a lifetime smoking and 3\%-5.6\% current prevalence of cigarette smoking among high-school adolescents in Addis Ababa [25].

Exposure to sexually explicit materials (SEM) means a picture, photograph, drawing, sculpture, motion picture film, or similar visual representation which is obscene for children. Pornography and SEM will be used interchangeably. Webster's dictionary defines pornography as "the depiction of erotic behavior intended to cause sexual excitement." Exposure to sexually explicit materials stands viewing sexually explicit material through media such as the Internet, videos, and magazines that may be directly linked with the sexual behavior of adolescents and young adults. Globally, adolescents spend more time with the media than they do in school or with their parents [26]. Much of what young people are listening to and/or watching includes sexual content. Males have been found to be more likely to expose themselves to SEMs than females. In Ethiopia, youths aged 15-24 years were more than 15.2 million, contributing to $20.6 \%$ of the whole population [27]. These large and productive groups of the population are exposed to various sexual and reproductive health risks. Among many sexual and reproductive health risks, sexual coercion, early marriage, polygamy, unplanned pregnancies, closely spaced pregnancies, abortion, and sexually transmitted infections (STIs) are the major ones [28].

Risk and protective factors for youth substance abuse should be assessed as a prevention program as they help decrease unhealthy behavior $[29,30]$. Individual protective 
factors, such as engagement in positive meaningful activities, positive self-concept, and religious or spiritual beliefs (religiosity) inhibit adolescent substance use. Peer protective factors, such as positive peer role models [31] also reduce adolescent substance use. Family factors that are found to be protective for adolescent substance use are connected to family (attachment/bonding), positive parenting style, living in a two parent family, higher parent education, and higher parental expectations about school. School protective factors include being connected to school (attachment/bonding), and caring school climate, and community protective factors are connected to other positive adults (bonded/attached), safe, supportive, connected neighborhoods, and community rewards for prosocial involvement [32].

Uses of substance and its consequence is one of the recent problems aggravate adolescents. The sustainable development goal (SDG) indicator, 3.5 targeted to strengthen the prevention and treatment of substance abuse, including narcotic drug abuse and harmful use of alcohol by the year 2030 [33].

Despite the fact that a number of researches have been done on substance uses, nowadays in Ethiopia many adolescent students and young adults migrate from rural to urban areas to attend secondary and higher educations or in search of job. This will in turn relate to risky sexual behavior. The prevalence of substance uses and exposure to risky sexual behavior is still high, and more effort is needed to minimize the rate of substance use and exposure to sexually risky materials. The finding of this study will help for the development of preventive policies, effective intervention priorities, and any cost benefit analysisrelated substance abuse and exposure to SEM. It will contribute to the literature by highlighting the influential characteristics of substance abuse and exposure to SEM by various social, economic, cultural, and demographic factors. It could also be part of baseline information for policy makers. Therefore, the main objective of this study is to assess the prevalence and associated factors of substance use and exposure to sexually explicit materials among high-school adolescents in North Shewa zone of Oromia regional state, Ethiopia (Figures 1 and 2).

\section{Methods}

2.1. Study Area. The study was conducted from March-May, 2019 in North Shewa zone of Oromia regional state, which is located around $114 \mathrm{~km}$ northwest of the capital Addis Ababa, with an elevation between 2515 and 2547 metres above sea level. Based on the 2007 census conducted by the Central Statistical Agency of Ethiopia (CSA), this zone has a total population of $1,431,305$, of whom 717,552 are men and 713,753 women; with a population density of 138.66 . Only $10.25 \%$ are urban inhabitants. The largest ethnic group of CSA reported on this area was Oromo (84.33\%) and followed by Amhara (14.99\%); all other ethnic groups made up $0.68 \%$ of the population.

2.2. Study Design. A cross-sectional study was conducted to assess substance abuse and exposure to sexually explicit materials (SEM) among high-school adolescents in North

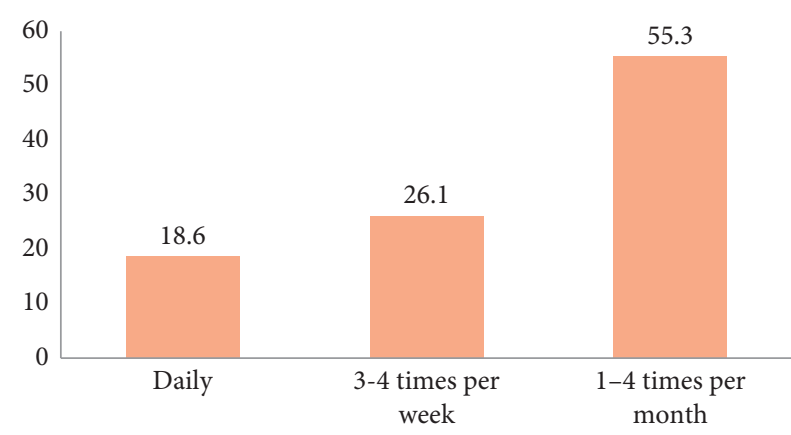

FIGURE 1: Frequency of watching sexually explicit materials.

Shewa zone, Oromiya, Ethiopia. A structured self-administered questionnaire will be adapted from the 2008 "Community That Care (CTC) Youth Survey" for adolescent substance uses and problem behaviors. Relevant modifications were made to incorporate information specific to this study and its local context. The data will be collected by trained data collectors and supervisors.

2.3. Target Population. The target population comprised all high-school adolescences aged 14-19 years. There were more than 10,000 high-school students in the north Shewa zone, Oromia region.

2.4. Study Population. All high-school adolescences were randomly selected from the target population.

2.5. Data Sample Size Determination. The sample size was determined using the formula of sample size determination for single population proportion considering $50 \%$ prevalence of substance use from prior similar study [21], assuming of $95 \%$ confidence interval, $5 \%$ marginal error, and $10 \%$ nonresponse rates.

$$
n=\frac{\left(z_{\alpha / 2}\right)^{2} p q}{d^{2}}
$$

where $n=$ sample size, $z_{\alpha / 2}=$ critical value to obtained from standard normal distribution, $\alpha=$ level of significance, $p=$ proportion of street children, and $d=$ margin of errors:

$$
n_{0}=\frac{\left(z_{\alpha / 2}\right)^{2} p q}{d^{2}}=\frac{(1.96)^{2} 0.5 * 0.5}{(0.05)^{2}}=385 .
$$

Then considering $10 \%$ nonresponse rate, the total sample size was $=\left(n_{0}+0.1 * n_{0}\right)=424$.

\section{Sampling Procedure}

3.1. Description of Data Collection Procedures. The survey used a two-stage simple random sampling technique. The first stage involved selecting schools in the study areas and the second stage, number of students per school was selected with a probability proportional to size. There were 14 districts in the North Shewa zone. The sampling frame was obtained from North Shewa zone education bureau. In the 


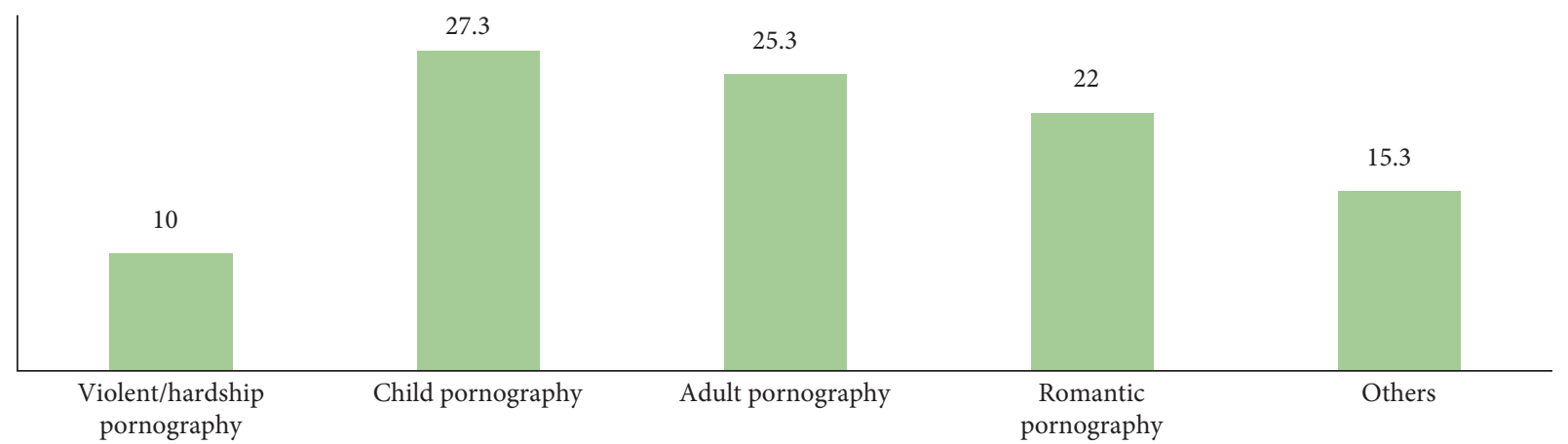

FIgURe 2: Percentage of sexually explicit materials consumed by most adolescents.

first stage, eight districts and one high school was selected within each district using simple random sampling technique. Accordingly the selected districts (schools) are Abichu (Mendida secondary school), Dera (Gundo meskel secondary school), Kuyu (Gebregurracha secondary school), Fiche (Abdissa Aga secondary school), Kimbibit (Sheno secondary school), Wechale (Mukaturi secondary school), Wara jarso (Tullu milki secondary school), and Debre Libanos (Derbretsige secondary school). In the second stage, a fixed number of students were selected using systematic random sampling technique. Sample size has been allocated for every grade based on proportional allocation to their size. Lastly, students from every class had been selected by systematic random sampling $(k=12)$.

3.2. Data Collection Procedure. The research instruments that were employed under this study adapted from the standard the 2008 "Community That Care Youth Survey" for adolescent substance use and problem behaviors and similar prior literatures. The data collectors were bachelor degree holders who have guided the students to fill the questionnaire. The data collectors briefed each question to the respondents to help them understand the question well and complete the questionnaire. The researchers have followed and facilitated the overall data collection process and trained the data collectors. The questionnaire is designed to gather qualitative and quantitative data pertaining to demographic, socioeconomic, and cultural factors and awareness and knowledge level on substance use.

3.3. Study Variables. The dependent variables are substance use and exposure to sexually explicit materials.

The independent variables were socio demographic characteristics (age, sex, grade, religion, mother's educational level, father's educational level, and family economic level), religiosity, friends' use of drugs/substances, poor family management (poor family discipline and poor family supervision, family conflict), family history of alcohol and substance use, poor academic performance/academic failure, low commitment to school, and perceived availability of substances.

3.4. Statistical Data Analysis. Descriptive statistics such as frequency distribution and cross tabulation and bar charts were used to summarize the distribution of selected characteristics of high school adolescents, while logistic regression analysis was employed to identify the statically significant factors of substance uses and exposure to sexually explicit materials among high-school adolescents.

3.5. Ethical Clearance. The study was undertaken after the approval of the research proposal by research and community service directorate of Salale University before the data collection started. A formal letter was written from Salale University to all the concerned authorities. For confidentiality, the name of the participants and ID number were not typed on the questionnaire. All responses were anonymous and kept confidential.

\subsubsection{Inclusion Criteria}

(i) All regular high-school students in the North Shewa zone, Oromia region

(ii) Adolescents ages between 14 and 19 years

\subsubsection{Exclusion Criteria}

(i) All students less than 14 years old and adolescents greater than 19 years old

\subsection{Operational Definition}

Adolescence. The period from age 14-19 years.

Substance. The three commonly used psychoactive drugs alcohol, cigarette, and khat that produce changes in mood, thinking, feeling, and/or behavior that can cause dependence.

Substance Use. Taking any of the three commonly used psychoactive substances: alcohol, cigarette, and/or khat in the past 30 days.

Risk Factors. Characteristics or conditions within the individual or in the family, school, or community that increase the likelihood that someone will engage in the use of alcohol, cigarette, and khat or discourage positive behavior that might prevent them [5].

Lifetime/Ever-Use. Adolescents' use of the particular substance at least once in their lifetime. 
Current Use/30-Day Uses. Adolescents' use of the substance at least once in the 30 days prior to data collection and is a more sensitive indicator of the level of current use of the substance.

\section{Results}

4.1. Description of Sample Characteristics. The total sample 424 identified 386 high school students fill the questionnaire with a response rate of $91 \%$. About $61 \%$ of the students included were male. Slightly more than half $56.5 \%$ of the respondents were grade 10 students. The vast majorities (87.4\%) of respondents were Coptic orthodox Christian and $39.2 \%$ were attending religious programs daily. About twothirds (66\%) were reported they had academic rank of 1-10 in the recent semester. $71.1 \%$ were living with their biological parents and $16.9 \%$ were living oneself. $53.7 \%$ and $62.1 \%$ of respondents were from father and mother with no formal education respectively. The age distribution of respondents showed that majority of the respondents $71.1 \%$ were in the age group 17-19 years old. The economic level of respondents' parents also varied, $64.3 \%$ of the respondents were from moderate income families, $20.5 \%$ were from poor families, and $15.2 \%$ were from families with high income status.

4.2. Prevalence of Substance Uses. Overall, 47.7\% (95\% CI: $0.427,0.527)$ of the respondents reported ever used any substance and $30.4 \%$ (95\% CI: $0.258,0.350)$ uses any substances in the past 30 days. $17.8 \%$ (95\% CI: $0.140,0.216)$ use khat in their life and $16.6 \%$ (95\% CI: $0.129,0.203)$ uses khat in the past 30 days, $42.2 \%$ (95\% CI: $0.373,0.471)$ ever used alcohol and 26.1\% (95\% CI: $0.217,0.305)$ currently uses alcohol, 4.8\% (95\% CI: $0.027,0.069)$ and 4.5\% (95\% CI: $0.024,0.066)$ uses cigarette in lifetime and in the past 30 days, while $16.4 \%$ (95\% CI: $0.127,0.201)$ use other illicit drugs in lifetime and $8.4 \%$ (95\% CI: 0.056, 0.0.112) use illicit drugs in the past 30 days, respectively. Distributions of substance use by sex indicate that male adolescents more likely (61.1\%) use substances than females.

Students are also asked to respond for how long they used substances. Accordingly, 35.5\% used substance for shorter than six months, $26.8 \%$ uses substance for six months to one year, $21.4 \%$ of respondents used substances for one to three years and $16.1 \%$ used substances for at least three years. Regarding the question where was the first place you consumed the drugs, $71 \%$ respond at home, $8.3 \%$ reported at khat or shisha store, $4.1 \%$ in school ground, $2.4 \%$ at party, and $14.3 \%$ were started using substance at bar or restaurant and others. Additionally, respondents were asked to rate the problem of drug uses in their school; $31.8 \%$ reported the problem is very high/very serious, $9.3 \%$ said it is somewhat serious, while $7.7 \%$ reported substance use is not too serious problem in school.

4.3. Motivation to Use Substance. The students were also asked to respond what motivates them to use substances. Accordingly, about $9.1 \%$ use substance due to peer pressure,
$13.4 \%$ due to academic failure, $15.1 \%$ to cope up with various life challenges, $18.8 \%$ to experience pleasure, and $22.5 \%$ of respondents motivated to use substance to be sociable. $30.8 \%$ of students reported they use khat to spend the leisure time, $16.9 \%$ being addicted, and $13.8 \%$ uses khat to be sociable. Similarly, $27.2 \%$ of adolescents use alcohol to pass the time, $6.4 \%$ use alcohol to leave depression, $10.4 \%$ to forget their problems, $13.6 \%$ report they use alcohol to be sociable, and $8 \%$ of the adolescents reported that they use alcohol being they are addicted.

4.4. Consequences of Substance Use. This study has found that substance use has various consequences. Concerning the behavioral consequences $12.5 \%, 15 \%, 16.7 \%$, and $6.7 \%$ of respondents were experienced lateness from school, violence (disciplinary problems), absenteeism from school, and loss of interest in daily activities as a result of using substances, respectively. On other hand, regarding the social aspects, $22.6 \%$ were experienced losing friends, 39.3\% experienced problems with parents/guardians and $7.1 \%$ being arrested due to substance use. Similarly, for heath related problems, $35.8 \%$ reported physically ill-health, $11.1 \%$ reported sleep disorder, and $16 \%$ experienced mental illness. From a total substance users $54.1 \%$ reported psychological distress and $11.2 \%$ were reported suicide attainment as psychological consequences of substance use. Generally, 26.9\%, 21.8\%, $10.3 \%$, and $9 \%$ of respondents experienced health-related problems, social problems, psychological problems, and behavioral problems consequences of substance use in their lifetime (Tables 1-3).

4.5. Assessment of Goodness of Fit of the Models. We start first by checking the overall goodness of fit using the likelihood ratio test and Hosmer-Lemeshow goodness of fit test. We then proceed to test the significance of each predictor variable included in the model using the Wald test. Accordingly, the results are summarized in Table 4, and the LRT based on chi-square distribution provided a significant test value $(p$ value $\leq 0.001)$ for both models. Additionally, the Hosmer-Lemeshow test revealed that there was a significance difference between the model with no covariate and the model with explanatory variables. A model with a covariate is a good fit to the data onto both models.

4.6. Factors Associated with Substance Use. In the multivariable logistic regression analysis, the variables sex, high level of family conflict, poor family management, age, low academic performance, substance use by friends, low level of school commitment, and mothers' education level showed a statistically significant association with adolescents' substance use.

Male adolescents were 2.334 times $(\mathrm{OR}=2.334,95 \% \mathrm{CI}$ : $1.549,9.926)$ more likely to use any substances than females. The odds of substance use were 27.084 times ( $\mathrm{OR}=27.084$, 95\% CI: 1.624, 45.56) higher among students with poor family management. Similarly, living through high levels of family conflict was positively associated with substance use 
TABLE 1: Socioeconomic, demographic and behavioral characteristics of adolescents.

\begin{tabular}{|c|c|c|c|}
\hline Characteristics & Categories & $N$ & $\%$ \\
\hline \multirow{2}{*}{ Sex } & Male & 230 & 61 \\
\hline & Female & 147 & 39 \\
\hline \multirow{2}{*}{ Grade } & $9^{\text {th }}$ & 164 & 43.5 \\
\hline & $10^{\text {th }}$ & 213 & 56.5 \\
\hline \multirow{4}{*}{ Living with } & Oneself & 61 & 16.9 \\
\hline & Parent & 256 & 71.1 \\
\hline & Relatives & 31 & 8.6 \\
\hline & Guardians/others & 12 & 3.3 \\
\hline \multirow{4}{*}{ Source of income } & Oneself & 52 & 14.4 \\
\hline & Parent & 264 & 79.2 \\
\hline & Relatives & 27 & 7.5 \\
\hline & Guardians/others & 19 & 5.2 \\
\hline \multirow{4}{*}{ Academic rank in the recent semester } & $1-10$ & 240 & 65.6 \\
\hline & $11-20$ & 89 & 24.3 \\
\hline & $21-30$ & 15 & 4.1 \\
\hline & $>30$ & 22 & 6 \\
\hline \multirow{4}{*}{ Religion } & Coptic orthodox & 322 & 87.4 \\
\hline & Muslim & 16 & 4.2 \\
\hline & Protestant & 20 & 5.3 \\
\hline & Others & 12 & 3.2 \\
\hline \multirow{6}{*}{ Frequency of attending religious program } & Daily & 145 & 39.2 \\
\hline & Once a week & 118 & 31.9 \\
\hline & More than twice a week & 56 & 15.1 \\
\hline & Once in two week & 19 & 5.1 \\
\hline & Once a month & 14 & 3.8 \\
\hline & Once in 6 months to one year & 18 & 4.9 \\
\hline \multirow{5}{*}{ Mother education level } & Illiterate & 148 & 40.3 \\
\hline & Read and write & 80 & 21.8 \\
\hline & Primary school & 61 & 16.6 \\
\hline & Secondary school & 37 & 10.1 \\
\hline & Higher education & 41 & 11.2 \\
\hline \multirow{5}{*}{ Father education } & Illiterate & 105 & 28.5 \\
\hline & Read and write & 93 & 25.2 \\
\hline & Primary school & 60 & 16.3 \\
\hline & Secondary school & 39 & 10.6 \\
\hline & Higher education & 72 & 19.5 \\
\hline \multirow{5}{*}{ Mother occupation } & Unemployed & 79 & 22.1 \\
\hline & Employed & 50 & 14 \\
\hline & Self-employed & 189 & 52.9 \\
\hline & Daily laborer & 15 & 4.2 \\
\hline & Others & 24 & 6.7 \\
\hline \multirow{5}{*}{ Father occupation } & Unemployed & 45 & 12.9 \\
\hline & Employed & 78 & 22.3 \\
\hline & Self-employed & 177 & 50.7 \\
\hline & Daily laborer & 21 & 6 \\
\hline & Others & 28 & 8 \\
\hline \multirow{3}{*}{ Family economic status } & Poor & 76 & 20.5 \\
\hline & Moderate & 238 & 64.3 \\
\hline & Rich & 56 & 15.1 \\
\hline
\end{tabular}

$(\mathrm{OR}=6.25,95 \% \quad \mathrm{CI}: 1.745,10.00)$ among adolescents keeping other variables constant. Adolescents whose friends use substance were more likely to use of substance than those who have friends who did not use substance $(\mathrm{OR}=11.928$, 95\% CI: 1.761, 18.692). As adolescents' age is, concerned adolescents aged 14-16 were at a lower risk of substance use compared to $17-19$ years old adolescents $(\mathrm{OR}=0.261,95 \%$
CI: $0.100,0.683)$. Those adolescents who had poor academic performance were more likely to use substance $(\mathrm{OR}=14.48$, $95 \%$ CI: $1.290,162.58)$ than those who performed well. The odds of substance uses were higher among adolescents who have reported low school commitment $(\mathrm{OR}=11.951,95 \%$ CI: $1.418,100.73)$. Further peer pressure from friends was another variable that significantly associated with substance 
TABLE 2: Lifetime and current use of different substances by sex among high school adolescents in North Shewa zone.

\begin{tabular}{|c|c|c|c|}
\hline \multirow{2}{*}{$\begin{array}{l}\text { Substance } \\
\text { Any substance }\end{array}$} & \multicolumn{2}{|c|}{ Sex } & \multirow[t]{2}{*}{ Total (\%) } \\
\hline & Male (\%) & Female (\%) & \\
\hline & $110(61.1)$ & $70(38.89)$ & $180(47.75)$ \\
\hline No & $120(60.91)$ & $77(39.1)$ & $197(52.25)$ \\
\hline \multicolumn{4}{|c|}{ Ever use of khat } \\
\hline Yes & $41(64.1)$ & $23(35.9)$ & $64(17.8)$ \\
\hline No & $175(59.3)$ & $120(40.7)$ & $295(82.2)$ \\
\hline \multicolumn{4}{|c|}{ Current use of khat } \\
\hline Yes & $39(63.93)$ & $22(36.07)$ & $61(16.6)$ \\
\hline No & $185(60.26)$ & $122(39.74)$ & $307(83.4)$ \\
\hline \multicolumn{4}{|c|}{ Ever use of alcohol } \\
\hline Yes & $90(57.69)$ & $66(42.31)$ & $156(42.16)$ \\
\hline No & $135(63.08)$ & $79(36.92)$ & $214(57.84)$ \\
\hline \multicolumn{4}{|c|}{ Current use of alcohol } \\
\hline Yes & $69(72.6)$ & $26(27.4)$ & $95(26.1)$ \\
\hline No & $153(56.9)$ & $116(43.1)$ & $269(73.9)$ \\
\hline \multicolumn{4}{|c|}{ Ever use of cigarette } \\
\hline Yes & $12(66.67)$ & $6(33.33)$ & $18(4.8)$ \\
\hline No & $208(66.88)$ & $130(33.12)$ & $311(95.2)$ \\
\hline \multicolumn{4}{|c|}{ Current use of cigarette } \\
\hline Yes & $10(62.5)$ & $6(37.5)$ & $16(4.5)$ \\
\hline No & $210(61.2)$ & $133(38.8)$ & $343(95.5)$ \\
\hline \multicolumn{4}{|c|}{ Ever use of illicit drugs } \\
\hline Yes & $40(66.67)$ & $20(33.33)$ & $60(15.9)$ \\
\hline No & $190(59.94)$ & $127(40.06))$ & $317(84.1)$ \\
\hline \multicolumn{4}{|c|}{ Current use of illicit drugs } \\
\hline Yes & $22(59.5)$ & $15(40.5)$ & $37(10.3)$ \\
\hline No & $194(60.2)$ & $128(39.8)$ & $322(89.7)$ \\
\hline
\end{tabular}

use. The odds of substance use were 12.882 times more likely $(\mathrm{OR}=12.882,95 \% \mathrm{CI}: 1.882,88.153)$ for those with peer pressure from friends than that of no peer pressure.

4.7. Prevalence of Exposure to SEM Uses. From the total adolescents included in the study, about 35.8\% (95\% CI: $0.310,0.406)$ were exposed to sexually explicit materials. The major sources of sexually explicit materials were mobile phone (38.3\%), video discs (14\%), Internet access/search $(14.5 \%)$, video houses $(7 \%)$, games $(5.4 \%)$, and magazines (2.8\%). The mean age of adolescents at the start of watching sexually explicit materials was 15.08 with \pm 3.307 standard deviation (SD). Regarding frequency of watching sexually explicit materials $18.6 \%$ reported they were watching SEM daily, $26.1 \%$ watch three to four times per week while $55.3 \%$ of respondents watch such materials one to four times a month.

Concerning to the question on sexually explicit materials consumed by most adolescents, $27.3 \%$ reported child pornography, $25.3 \%$ adult pornography, and $22 \%$ romantic pornography. $24.8 \%$ of respondents were watching/read pornographic materials alone, while $43.3 \%$ and $17.7 \%$ were watching such materials with friends and families, respectively.

Regarding access to sexually explicit materials, the vast majority $61.5 \%$ of adolescents download sexually explicit materials from their mobile phone while $17.3 \%$ get from
TABLE 3: Major motivations and reasons to use substances.

\begin{tabular}{lcc}
\hline & $\mathrm{N}$ & $\%$ \\
\hline Basic motivations to use drugs & 30 & 9.1 \\
Peer pressure & 29 & 9 \\
Availability of drugs & 41 & 13.4 \\
Academic failure & 36 & 11.7 \\
Dissatisfaction with the school environment & 39 & 12.4 \\
Having biological relatives with drug abuse & 42 & 13.4 \\
Unhappiness at home & 47 & 15.1 \\
To cope with various life challenges & 58 & 18.8 \\
To experience pleasure & 69 & 22.5 \\
To socialize & & \\
Major reason for khat chewing & 20 & 30.8 \\
To pass the time & 8 & 12.3 \\
To stay awake & 9 & 13.8 \\
To socialize & 11 & 16.9 \\
Being addicted & 17 & 26.2 \\
Others & & \\
Major reason for using alcohol & 34 & 27.2 \\
To pass the time & 8 & 6.4 \\
Depression & 13 & 10.4 \\
To forget problems & 17 & 13.6 \\
To socialize & 10 & 8 \\
Being addicted & 43 & 34.4 \\
Others &
\end{tabular}

TABle 4: Overall model goodness of fit checking using likelihood test and Hosmer-Lemeshow test.

\begin{tabular}{lcccc}
\hline Model 1 & $-2 \log$ likelihood & Likelihood ratio test & df & $p$ value \\
\hline Null model & 187.474 & 58.27 & 29 & 0.001 \\
Full model & 129.204 & & & \\
\hline Hosmer-Lemeshow test $=10.196(p$ value $=0.253)$ \\
\hline Model 2 & $-2 \log$ likelihood & Likelihood ratio test & df & $p$ value \\
Null model & 184.241 & 49.395 & 28 & $<0.001$ \\
Full model & 134.846 & & & \\
\multicolumn{4}{l}{ Hosmer-Lemeshow test $=11.333(p$ value $=0.184)$} \\
\hline
\end{tabular}

Internet cafes. As practice of SEM is concerned, 19.3\% of adolescents had practiced what they had seen/read from sexually explicit materials. Concerning exposure to sexually explicit materials by sex, $71.1 \%$ adolescents exposed to sexually explicit materials were male adolescents. Among adolescents who drink alcohol, 51.4\% were exposed to SEM while $33.3 \%$ and $31.9 \%$ of adolescents chewing khat and using other illicit drugs, were reported they were exposed to SEM, respectively.

4.8. Factors Associated with Exposure to Sexually Explicit Materials. The multivariate logistic regression analysis presented in Table 5 indicates that the odds of being exposed to SEM were 7.52 times $(\mathrm{OR}=7.52,95 \% \mathrm{CI}$ : 2.611, 21.739) more likely among male students than females. Adolescents who are aged between 14 and 16 years old had a significant lower odds of being exposed to sexually explicit materials $(\mathrm{OR}=0.201,95 \% \mathrm{CI}: 0.071,0.565)$ than adolescents $17-19$ years old. Adolescents whose friends watch/read SEM were 0.186 times $(\mathrm{OR}=0.186,95 \% \mathrm{CI}: 0.035,0.990)$ more likely 
exposed to sexually explicit materials than those whose friends did not watch SEM (Tables 6 and 7).

As family educational status is concerned, those adolescents whose father had secondary education level were 7.996 times ( $\mathrm{OR}=7.996,95 \% \mathrm{CI}: 1.010,63.306)$ less exposed than those whose father had attained a diploma or higher education. Adolescents whose mother did not work and selfemployed had less exposed to SEM $(\mathrm{OR}=25.151,95 \% \mathrm{CI}$ : $3.290,192.293)$ and $(\mathrm{OR}=6.577,95 \% \mathrm{CI}: 1.013,42.721)$, respectively. Similarly, regressing family economic status, the odds of exposure to sexually explicit materials among adolescents that belongs to a household with poor $(\mathrm{OR}=8.433,95 \% \mathrm{CI}: 1.647,43.18)$ and moderate $(\mathrm{OR}=3.948,95 \% \mathrm{CI}: 1.088,14.327)$ income levels was less than that of rich income.

\section{Discussion}

The lifetime prevalence of substance uses was $47.75 \%$ and the prevalence of current substance use is $30.4 \%$. The finding of this study is lower than studies conducted in Haramaya university [13] that reported $62.4 \%$ of lifetime prevalence of substance use, in Woreta Town [22] that reported $65.4 \%$ prevalence of lifetime substance use and $47.9 \%$ prevalence of current substance use among high school students, a study conducted in Woldia Town [21] reported 50\% prevalence of current substance, and in Kenya [34] that reported $69.8 \%$ of lifetime substance use, but higher than finding of a systematic review and meta-analysis study in sub-Saharan Africa [14] that reported $41.6 \%$ of lifetime prevalence of substance use, in Sri Lanka [35] that reported 2.7\% prevalence of lifetime substance use, in India [36] that reported $12.5 \%$ prevalence of life time substance use, in Southeast Asia [19] that reported $16.9 \%$ of lifetime drug use, and in Nepal [18] that reported $6 \%$ prevalence current substance use. A study conducted in Rift Valley University [37] also reported a slightly lower $44.8 \%$ prevalence of lifetime substance use and a higher prevalence of current substance use $39.1 \%$. The reason for this difference may be the difference in culture, accessibility of drugs, and variation in ages of study sample. In line with prior studies $[13,15,21]$, this study found that the prevalence of current and lifetime substance use is higher among males.

In the current study, the prevalence of a lifetime and current alcohol use was $42.16 \%$ and $26.1 \%$, which is congruent with a study in Uganda [38] that reported $26.8 \%$ of current alcohol users and is lower than a study done in Woreta Town [22] that reported $40.9 \%$ and $59 \%$ prevalence of current and life time prevalence of alcohol use, while a similar study conducted in Sri Lanka reported a lower prevalence of alcohol uses (3.4\%) [35]. The current and lifetime prevalence of khat chewing was $16.6 \%$ and $17.8 \%$. This result is lower than the result of a study done among Haramaya University students [13] $23.6 \%$ and $41 \%$, respectively, a study done in preparatory students in Woldia Town [21] 23.5\%, a study in Rift Valley University 35.6\% [37], and a study conducted in Saudi Arabia that reported $48.8 \%$ of lifetime khat chewing and $33.9 \%$ current khat
TABLE 5: Major consequences of substance.

\begin{tabular}{lcc}
\hline Consequences of substance & $\mathrm{N}$ & $\%$ \\
\hline Health aspects & 29 & \\
Physically ill-health & 9 & 35.8 \\
Sleep disorder & 13 & 11.1 \\
Mental illness & 30 & 16 \\
Others & & 37.1 \\
\hline Social aspects & 19 & \\
Loosing friends & 33 & 22.6 \\
Problems with parents/guardians & 6 & 39.3 \\
Being arrested & 26 & 7.1 \\
Others & & 31 \\
\hline Behavioral aspects & 15 & \\
Lateness from school & 18 & 12.5 \\
Violence (disciplinary problems) & 20 & 15 \\
Absenteeism from school & 8 & 16.7 \\
Loss of interest in daily activities & 59 & 6.7 \\
Others & & 49.7 \\
\hline Psychological aspects & 53 & \\
Psychological distress & 11 & 54.1 \\
Suicide attainment & 44 & 11.2 \\
Others & & 34.7 \\
\hline
\end{tabular}

chewing [39]. This variation may be because the accessibility of substances and difference in culture from region to region.

The magnitude of the prevalence lifetime and current cigarettes smoking were almost similar $4.8 \%$ and $4.5 \%$, respectively. This finding is lower than a study in Woldia Town 23.5\% [21] and a study in Addis Ababa University students 9\% [15], and a study in Rift Valley University $18.4 \%$ [37], but higher than a study in Sri Lanka 2.3\% [35]. This small prevalence in this study may be attributed to underreporting due to self-reporting or it might be because of the differences in study setting and population. The lifetime prevalence of illicit drug uses for this particular study is $16.4 \%$ the prevalence of current illicit drug uses is $8.4 \%$. The finding of this study is almost with a study conducted in Haramaya University [13] that reported $17.4 \%$ of lifetime use of illicit drugs and $7.4 \%$ of current use of illicit substance use.

In the multivariable logistic regression analysis, the study found significant associations between substance and sex, living through high levels of family conflict, poor family management, age, friends' use of substance, poor academic performance, low school commitment, and illiterate education level of mother. Similarly, exposure to sexually explicit materials was strongly associated with sex, age, friends watching SEM, father education level, mother occupation, family's economic status, and chewing khat. Substance use was highly probable among male students compared to females. Male students were more likely to use substances than females. This finding agrees with earlier researches $[13,15,20,38]$ while some researchers found there is no significant association with substance and sex [18, 21]. In this study, students whose friends use substance were more likely to use substances as compared to that of whose friends did not use. This finding agrees with previous studies conducted in Addis Ababa University [15], Woreta Town [22], Woldia 
TABLE 6: Factors associated with life time substance use among high school adolescents in North Shewa zone.

\begin{tabular}{|c|c|c|c|c|c|}
\hline \multirow{2}{*}{ Variables } & \multicolumn{2}{|c|}{ Substance use } & \multirow{2}{*}{ AOR } & \multirow{2}{*}{$95 \% \mathrm{CI}$ for $\mathrm{AOR}$} & \multirow{2}{*}{$p$ value } \\
\hline & $N$ & $\%$ & & & \\
\hline \multicolumn{6}{|l|}{ Sex } \\
\hline Male & 110 & 61.1 & 2.334 & $1.549,9.926$ & $0.002^{*}$ \\
\hline Female & 70 & 38.9 & 1 & & \\
\hline \multicolumn{6}{|c|}{ Living through high levels of family conflict } \\
\hline Yes & 29 & 17.4 & 6.25 & $1.745,10.00$ & $0.023^{*}$ \\
\hline No & 138 & 82.6 & 1 & & \\
\hline \multicolumn{6}{|l|}{ Poor family management } \\
\hline Yes & 42 & 25.1 & 27.084 & $1.624,45.56$ & $0.022^{*}$ \\
\hline No & 125 & 74.9 & 1 & & \\
\hline \multicolumn{6}{|c|}{ Pressure from my friends to use substance } \\
\hline Yes & 41 & 23.8 & 12.882 & $1.882,88.153$ & $0.009^{*}$ \\
\hline No & 131 & 76.2 & 1 & & \\
\hline \multicolumn{6}{|l|}{ Friends use of substances } \\
\hline Yes & 25 & 14.3 & 11.928 & $1.761,18.692$ & $0.007^{*}$ \\
\hline No & 150 & 85.7 & 1 & & \\
\hline \multicolumn{6}{|l|}{ Age } \\
\hline $14-16$ & 35 & 24.3 & 0.261 & $0.100,0.683$ & $0.006^{*}$ \\
\hline $17-19$ & 109 & 75.7 & 1 & & \\
\hline \multicolumn{6}{|c|}{ Access of substances near your school } \\
\hline Yes & 41 & 26.3 & 1.062 & $0.128,8.787$ & 0.956 \\
\hline No & 115 & 73.7 & 1 & & \\
\hline \multicolumn{6}{|c|}{ Poor academic performance } \\
\hline Yes & 35 & 21.6 & 14.48 & $1.290,162.58$ & $0.030^{*}$ \\
\hline No & 127 & 78.4 & 1 & & \\
\hline \multicolumn{6}{|l|}{ Low school commitment } \\
\hline Yes & 39 & 24.5 & 11.951 & $1.418,100.73$ & $0.033^{*}$ \\
\hline No & 120 & 75.5 & 1 & & \\
\hline \multicolumn{6}{|c|}{ Family history of substance use } \\
\hline Yes & 32 & 19.6 & 5.915 & $0.748,46.773$ & 0.092 \\
\hline No & 131 & 80.4 & 1 & & \\
\hline \multicolumn{6}{|l|}{ Family economic status } \\
\hline Poor & 39 & 22 & 0.405 & $0.033,5.052$ & 0.483 \\
\hline Moderate & 110 & 62.1 & 3.699 & $0.500,27.358$ & 0.200 \\
\hline Rich & 28 & 15.8 & 1 & & \\
\hline \multicolumn{6}{|l|}{ Mother's education } \\
\hline Illiterate/read and write & 117 & 65.7 & 2.051 & $0.068,61.564$ & 0.051 \\
\hline Primary & 33 & 18.5 & 2.165 & $0.074,62.981$ & 0.653 \\
\hline Secondary & 13 & 7.3 & 1.584 & $0.044,56.408$ & 0.053 \\
\hline Diploma/higher & 15 & 8.4 & 1 & & \\
\hline \multicolumn{6}{|l|}{ Father's education } \\
\hline Illiterate/read and write & 107 & 61.1 & 2.936 & $0.553,15.588$ & 0.206 \\
\hline Primary & 23 & 13.1 & 2.868 & $0.256,28.212$ & 0.410 \\
\hline Secondary & 20 & 11.4 & 0.053 & $0.002,1.410$ & 0.053 \\
\hline Diploma/higher & 25 & 14.3 & 1 & & \\
\hline
\end{tabular}

Town [21], Wolaita Sodo University [40], and Addigrat University [23].

This study shows that substance use is associated with poor family management and living through high level of conflict. Students who are living through high level of conflicts are more likely to use substances. Findings from previous research [41] suggest using substances was higher among adolescents living through high level of conflict. Poor family management was also directly associated with adolescents using substance, where adolescents that belong to poor family managements have a higher odd of using substances. This finding was consistent with the result of $[42,43]$.

Poor academic performance was another variable identified as a significant predictor of substance uses among adolescents in the multivariate analysis. The findings show that adolescents with poor academic performance have a significantly higher odds of substance compared to those with good academic performance. This finding was consistent with the result of $[39,42]$ that lower achievers had a high likelihood of using substances. Additionally, low school commitment and mother's education level was found to be 
TABLE 7: Factors associated with high school adolescents' exposure to sexually explicit materials in North Shewa zone.

\begin{tabular}{|c|c|c|c|c|c|}
\hline & & & & & \\
\hline & $N$ & $\%$ & AOR & $95 \% \mathrm{Cl}$ for AOR & $p$ values \\
\hline Sex & & & & & \\
\hline Male & 96 & 71.1 & 7.52 & $2.611,21.739$ & $<0.0001^{*}$ \\
\hline Female & 36 & 28.9 & 1 & & \\
\hline Grade & & & & & \\
\hline & 57 & 44.2 & 1.214 & $0.521,2.831$ & 0.653 \\
\hline $10^{\text {th }}$ & 72 & 55.8 & 1 & & \\
\hline Positive parental role mo & & & & & \\
\hline Yes & 44 & 34.9 & 0.519 & $0.177,1.523$ & 0.232 \\
\hline No & 82 & 65.1 & 1 & & \\
\hline Peer pressure & & & & & \\
\hline Yes & 34 & 25.6 & 1.986 & $0.502,7.865$ & 0.328 \\
\hline No & 99 & 74.4 & 1 & & \\
\hline Age & & & & & \\
\hline $14-16$ & 34 & 32.7 & 0.201 & $0.071,0.565$ & $0.002^{*}$ \\
\hline $17-19$ & 70 & 67.3 & 1 & & \\
\hline Friends watch SEM & & & & & \\
\hline Yes & & & 5.376 & $1.010,28.571$ & $0.049^{*}$ \\
\hline No & & & 1 & & \\
\hline Poor academic performar & & & & & \\
\hline Yes & 33 & 30 & 0.491 & $0.154,1.561$ & 0.228 \\
\hline No & 77 & 70 & 1 & & \\
\hline School commitment & & & & & \\
\hline Yes & 29 & 26.6 & 1.413 & $0.364,5.479$ & 0.617 \\
\hline No & 80 & 73.4 & 1 & & \\
\hline Mother education status & & & & & 0.163 \\
\hline Illiterate & 58 & 43 & 0.585 & $0.052,6.619$ & 0.665 \\
\hline Read and write & 36 & 26.7 & 0.588 & $0.053,6.496$ & 0.665 \\
\hline Primary school & 17 & 12.6 & 1.219 & $0.098,15.151$ & 0.878 \\
\hline Secondary school & 14 & 10.4 & 0.136 & $0.012,1.543$ & 0.107 \\
\hline Diploma/higher & 10 & 7.4 & 1 & & \\
\hline Father education status & & & & & \\
\hline Illiterate & 41 & 31.1 & 0.651 & $0.130,3.274$ & 0.603 \\
\hline Read and write & 42 & 31.8 & 0.378 & $0.085,1.682$ & 0.202 \\
\hline Primary school & 19 & 14.4 & 1.753 & $0.293,10.479$ & 0.538 \\
\hline Secondary school & 11 & 8.3 & 7.996 & $1.010,63.306$ & $0.049^{*}$ \\
\hline Diploma/higher & 19 & 14.4 & 1 & & \\
\hline Mother's occupation & & & & & $0.022^{*}$ \\
\hline Not working & 28 & 22 & 25.151 & $3.290,192.293$ & $0.002^{*}$ \\
\hline Employed & 15 & 11.8 & 4.804 & $0.598,38.626$ & 0.140 \\
\hline Self-employed & 61 & 48 & 6.577 & $1.013,42.721$ & 0.048 \\
\hline Daily laborer & 8 & 6.3 & 7.436 & $0.539,102.66$ & 0.134 \\
\hline Others & 15 & 11.8 & 1 & & \\
\hline Family economic status & & & & & $0.036^{*}$ \\
\hline Poor & 21 & 15.9 & 8.433 & $1.647,43.18$ & $0.011^{*}$ \\
\hline Moderate & 83 & 62.9 & 3.948 & $1.088,14.327$ & $0.037^{*}$ \\
\hline Rich & 28 & 21.2 & 1 & & \\
\hline Chew khat & & & & & \\
\hline Yes & 45 & 33.3 & 12.5 & $2.924,52.632$ & $0.001^{*}$ \\
\hline No & 90 & 66.7 & 1 & & \\
\hline Use alcohol & & & & & \\
\hline Yes & 71 & 51.4 & 0.344 & $0.036,3.291$ & 0.354 \\
\hline No & 67 & 48.6 & 1 & & \\
\hline Use other illicit substance & & & & & \\
\hline Yes & 44 & 31.9 & 1.182 & $0.130,10.766$ & 0.882 \\
\hline No & 94 & 68.1 & 1 & & \\
\hline
\end{tabular}


significant covariates of substance use. Adolescents from schools with low commitment to control drugs and follow students more likely to use substance [44] while [45] found that there is no association with school commitment and substance use. Adolescents belong to mothers' with no education at all had a higher odds of using substance compared to those belongs to mothers of higher education. This finding is in agreement with prior studies in Korea [46] which shows a significant association with maternal education and drug uses. Age of adolescents was another variable significantly associated with substance use. The odds of substance uses were higher among adolescent 17-19 years old compared to that of 14-16 years. This finding is congruent with a study conducted in Sri Lanka $[35,47,48]$.

This study also found that friends' use of sexually explicit material has increased rates of exposure to sexually explicit materials among adolescents, which was congruent with previous studies [49]. This event may be due to high peer pressure and initiation to be sociable with friends. Sex was another variable found to be significantly associated with adolescents' exposure to sexually explicit materials. The rate of exposure to sexually explicit material was higher among male adolescents than females. A previous studies had reported that being male was associated with increased risk of exposure to SEM than females [49-53]. Exposure to sexually explicit materials was also inversely associated with family economic status. This may due the fact that children belonging to rich family had access to different Internet and videos discs. This finding was consistent with earlier studies [52]. Mothers' occupation was also found to significantly associate with adolescents exposure to SEM. Higher odds of exposure to sexually explicit materials existed among mothers who were not working and self-employed. This finding is consistent with a study conducted among preparatory students in Addis Ababa [52].

Khat chewing was also an important factor that significantly related to adolescents exposure to sexually explicit materials. It is vital that use of khat and other illicit drugs initiate adolescents to read/watch pornographic materials. The findings of this study showed that adolescents who chew khat were probably highly exposed to SEM than those who had not chewing khat. Existing literature also indicates that khat chewing and using drug had a higher access to get exposure to SEM $[49,50,53]$. The findings of the study also revealed that adolescents 17-19 years old were more likely exposed to SEM. A study conducted by $[54,55]$ indicated that adolescents age has a significant association with sexually explicit content on the Internet. Exposure to sexually explicit materials was also significantly higher among adolescents born to a father with a secondary education compared to that of a diploma or higher. This finding is congruent with a study by [56].

The study did not find a significant association between grade levels, access of substance near school, family history of substance use, family economic status and substance use, which was inconsistent with prior studies on determinants of substance use $[13,18,22]$. Peer pressure, poor family management, academic performance, mother's education level, use of alcohol, and use of illicit substances were not significantly associated exposure to SSEM. However, this finding differs from earlier studies [49-51].

\section{Conclusion}

The study has examined the prevalence and factors associated with high-school adolescents' substance use and exposure to sexually explicit materials in North Shewa zone Oromia region using logistic regression analysis. The finding of this study supports that the prevalence of substance use and exposure to sexually explicit materials among high school adolescents is still high and is an important public health issue in the study area. In the results of multivariable logistic regression analysis, it was found that being male sex, living through high levels of family conflict, poor family management, friends' use of substance, poor academic performance, adolescents age 17-19 years, and low school commitment were factor significantly increase the risk of substance uses. On the other hand, being male sex, adolescents age 17-19 years, having friends watching sexually explicit materials, father's education level, family's economic status, and chewing khat were factors strongly positively correlated with high school adolescents exposure to sexually explicit materials.

To achieve the sustainable development goal indicator, 3.5 targeted to strengthen the prevention and treatment of substance abuse, interventions that focus on family management, peer pressure, and school commitment are required to decrease the prevalence of substance uses and exposure to sexually explicit materials among high-school adolescents.

\section{Strength and Limitations of the Study}

This study used a questionnaire adapted from the standard the 2008 "Community That Care Youth Survey" for adolescent substance use and problem behaviors. The major limitation was that misreporting or underreporting of illicit drugs uses. Also the study included only students studying in school. The other limitation was that interaction effects were not used included in the analysis due to large number of variables to compute.

\section{Data Availability}

The data used to support the findings of this study are available from the corresponding author upon request.

\section{Conflicts of Interest}

The authors declare that they have no conflicts of interest.

\section{References}

[1] A. O. Odejide, "Status of drug use/abuse in Africa: a review," International Journal of Mental Health and Addiction, vol. 4, no. 2, pp. 87-102, 2006.

[2] World Health Organization, Substance Use in South Africa: Knowledge, Attitudes, Practices, and Opportunities for 
Intervention, WHO, Geneva, Switzerland, 2003, http://www. who.int/mental_health/media/en/707.pdf.

[3] World Health Organization, Global Status Report on Alcohol 2004, WHO, Geneva, Switzerland, 2004.

[4] L. R. Gowing, R. L. Ali, S. Allsop et al., "Global statistics on addictive behaviours: 2014 status report," Addiction, vol. 110, no. 6, pp. 904-919, 2015.

[5] N. D. Volkow and T. K. Li, "Drugs and alcohol: treating and preventing abuse, addiction and their medical consequences," Pharmacology \& Therapeutics, vol. 108, no. 1, pp. 3-17, 2005.

[6] World Health Organization, Global Status Report on Alcohol and Health-2014, WHO, Geneva, Switzerland, 2014, ISBN 9789240692763.

[7] O. G. Bukstein, W. Bernet, V. Arnold et al., "Practice parameter for the assessment and treatment of children and adolescents with substance use disorders," Journal of the American Academy of Child \& Adolescent Psychiatry, vol. 44, no. 6, pp. 609-621, 2005.

[8] Y. Kebede and T. Abula, Substance Abuse for the Ethiopian Health Center Team 1, Addis Ababa: Ethiopian Public Health Training Initiative, Ethiopia, 2005.

[9] EPHA, Young People's HIV/AIDS \& Reproductive Health Needs and Utilization of Services in Selected Regions of Ethiopia, Addis Ababa, Ethiopia, 2005.

[10] BSS, "HIV/AIDS behavioral surveillance survey Ethiopia: round two. MOH, HAPCO, AAU, CSA, EPHA," Addis Ababa, Ethiopia, 2005.

[11] Central Statistical Agency (CSA) (Ethiopia) and ICF, Ethiopia Demographic and Health Survey 2016, Addis Ababa, Ethiopia, and Rockville, CSA and ICF, MD, USA, 2016.

[12] G. Tadele, Young Men, Sexuality and HIV/AIDS in an Ethiopian Town, African Study Center, Leiden, Netherlands, 2006.

[13] G. Tesfaye, A. Derese, and M. T. Hambisa, "Substance use and associated factors among university students in Ethiopia: a cross-sectional study," Journal of Addiction, vol. 2014, 2014.

[14] A. Olawole-Isaac, O. Ogundipe, E. O. Amoo, and D. Adeloye, "Substance use among adolescents in sub-Saharan Africa: a systematic review and meta-analysis," South African Journal of Child Health, vol. 12, no. 1, pp. S79-S84, 2018.

[15] W. Deressa and A. Azazh, "Substance use and its predictors among undergraduate medical students of Addis Ababa University in Ethiopia," BMC Public Health, vol. 11, no. 1, p. 660, 2011.

[16] T. B. Gebremariam, K. B. Mruts, and T. K. Neway, "Substance use and associated factors among Debre Berhan University students, Central Ethiopia," Substance Abuse Treatment, Prevention, and Policy, vol. 13, p. 13, 2018.

[17] Shimelis Keno Tulu and W. Keskis, "Assessment of causes, prevalence and consequences of alcohol and drug abuse among Mekelle university, CSSL 2nd year students," American Journal of Applied Psychology, vol. 3, no. 3, pp. 47-56, 2015.

[18] A. Gurung, N. Shrestha, M. Silwal, R. Gurung, and S. Ojha, "Prevalence of substance use and associated factors among high school adolescents in rithepani, Lekhnath-2, kaski, Nepal," Journal of Gandaki Medical College-Nepal, vol. 10, no. 1, pp. 43-48, 2017.

[19] S. Yi, K. Peltzer, S. Pengpid, and I. H. Susilowati, "Prevalence and associated factors of illicit drug use among university students in the association of southeast Asian nations (ASEAN)," Substance Abuse Treatment, Prevention, and Policy, vol. 12, p. 9, 2017.

[20] D. B. Mamo, D. A. Abuhay, B. K. Gelaw, and G. T. Tegegne, "Assessment on the prevalence and contributing factors of social drugs utilization among university of Gondar regular undergraduate students, maraki campus, 2013," International Journal of Pharma Sciences and Research (IJPSR), vol. 5, no. 8, 2014, ISSN: 0975-9492.

[21] A. Gobeje, G. Measo, A. Ageb, and T. Chanie, "Prevalence of substance use and associated factors among preparatory students of N/Wollo Woldia Town, north east Ethiopia, 2015," Acta Scientific Nutritional Health, vol. 3, pp. 25-33, 2019.

[22] A. M. Birhanu, T. A. Bisetegn, and S. M. Woldeyohannes, "High prevalence of substance use and associated factors among high school adolescents in Woreta Town, Northwest Ethiopia: multi-domain factor Analysis," BMC Public Health, vol. 14, p. 1186, 2014.

[23] H. Gebremedhin, G. Gebreegziabiher, and B. Desalegn, "Prevalence of substance abuse and associated factors among university students, Tigray, Ethiopia, 2016," International Journal of Development Research, vol. 6, no. 11, pp. 1006610071, 2016.

[24] A. Reda, "Determinant of tobaco use among school adolescents in eastern Ethiopia: a cross - sectional study, 2010," in Proceedings of the 22nd Ethiopian Public Health Association Conference, Addis Ababa, Ethiopian Public Health Association (EPHA), Ethiopia, October 2011.

[25] Drug Administration and Control Authority of Ethiopia, "A report on global youth tobacco survey (GYTS) conducted in secondary schools in Addis Ababa-Ethiopia, Addis Ababa," Drug Administration and Control Authority, Ethiopia, 2005.

[26] L. Gruber and H. Thau, "Sexually-related content on television and adolescents of color: media theory, physiological development, and psychological impact," The Journal of Negro Education, vol. 72, no. 4, pp. 438-456, 2003.

[27] Federal Democratic Republic of Ethiopia Population Census Commission, Summary and Statistical Report of 2007 Population and Housing Census, 2007.

[28] E. Scholl, J. Schueller, M. Gashaw, A. Wagaw, and L. Woldemichael, Assessment of Youth Reproductive Health Programs in Ethiopia, 2004.

[29] F. A. Sawair, A. Al-Mutwakel, K. Al-Eryani et al., "High relative frequency of oral squamous cell carcinoma in Yemen: qat and tobacco chewing as its aetiological background," International Journal of Environmental Health Research, vol. 17, no. 3, pp. 185-195, 2007.

[30] L. Bond, J. Toumbourou, L. Thomas, R. Catalano, and G. Patton, "Individual, family, school, and community risk and protective factors for depressive symptoms in adolescents: a comparison of risk profiles for substance use and depressive symptoms," Prevention Science, vol. 6, no. 2, pp. 73-88, 2005.

[31] R. F. Oman, S. Vesely, C. B. Aspy, K. R. McLeroy, S. Rodine, and L. Marshall, "The potential protective effect of youth assets on adolescent alcohol and drug use," American Journal of Public Health, vol. 94, no. 8, pp. 1425-1430, 2004.

[32] E. J. M. Pennings, A. Opperhuizen, and J. G. C. van Amsterdam, "Risk assessment of khat use in The Netherlands: a review based on adverse health effects, prevalence, criminal involvement and public order," Regulatory Toxicology and Pharmacology, vol. 52, no. 3, pp. 199-207, 2008.

[33] United Nations General Assembly, Transforming Our World: The 2030 Agenda for Sustainable Development, United Nations, New York, NY, USA, 2015, http://www.un.org/ga/ search/view_doc.asp?symbol=A/RES/70/1\&Lang=E.

[34] L. Atwoli, P. A. Mungla, M. N. Ndungu, K. C. Kinoti, and E. M. Ogot, "Prevalence of substance use among college 
students in Eldoret, western Kenya," BMC Psychiatry, vol. 11, no. 1, p. $34,2011$.

[35] S. Senanayake, S. Gunawardena, M. Kumbukage et al., "Smoking, alcohol consumption, and illegal substance abuse among adolescents in Sri Lanka: results from Sri Lankan global school-based health survey 2016," Advances in Public Health, vol. 2018, Article ID 9724176, 7 pages, 2018.

[36] R. Pal, A. Dasgupta, and D. Tsering, "Substance use among adolescent high school students," Journal of Pharmacy \& Bioallied Sciences, vol. 2, no. 2, p. 137, 2010.

[37] S. T. Kumesa, M. A. Mohammed, E. T. Gebremariam, B. K. Gelaw, and M. F. Seifu, "The prevalence and pattern of social drug abuse among students of Rift Valley university college, Bishoftu campus, 2014, Bishoftu, Ethiopia," Journal of Pharmaceutical Care \& Health Systems, vol. 2, no. 1, p. 131, 2015.

[38] S. N. Kabwama, S. Ndyanabangi, G. Mutungi, R. Wesonga, S. K. Bahendeka, and D. Guwatudde, "Alcohol use among adults in Uganda: findings from the countrywide non-communicable diseases risk factor cross-sectional survey," Global Health Action, vol. 9, Article ID 31302, 2016.

[39] J. Gaete, G. Rojas, R. Fritsch, and R. Araya, "Association between school membership and substance use among adolescents," Frontiers in Psychiatry, vol. 9, p. 25, 2018.

[40] T. Mekonen, W. Fekadu, T. Chane, and S. Bitew, "Problematic alcohol use among university students," Frontiers in Psychiatry, vol. 8, p. 86, 2017.

[41] P. Pokhrel, S. Sussman, P. Sun, V. Kniazer, and R. Masagutov, "Social self-control, sensation seeking and substance use in samples of US and Russian adolescents," American Journal of Health Behavior, vol. 34, no. 3, pp. 374-384, 2010.

[42] R. O. Ajala and F. T. Odunyemi, "Pattern of drug use among adolescents in selected secondary schools in ibadan north local government area, ibadan Oyo state Nigeria," Journal of Nursing and Health Science, vol. 7, no. 4, pp. 46-54, 2018.

[43] E. Rudatsikira, D. Maposa, Z. Mukandavire, A. S. Muula, and S. Siziya, "Prevalence and predictors of illicit drug use among school-going adolescents in Harare, Zimbabwe," Annals of African Medicine, vol. 8, no. 4, pp. 215-220, 2009.

[44] A. O. Boker Agili, I. W. Ali Hakami, T. A. Abu Rajeh Kariri, A. J. Essa Alhagawy, M. A. Ahmed Majrashi, and M. A. Mohammed Abdulfattah, "Determination of the prevalence of khat chewing among students of the high school in Jazan city, Saudi Arabia," World Journal of Pharmacy and Pharmaceutical Sciences, vol. 7, no. 3, 2018.

[45] K. Riva1, L. Allen-Taylor, W. D. Schupmann, S. Mphele, N. Moshashane, and E. D. Lowenthal, "Prevalence and predictors of alcohol and drug use among secondary school students in Botswana: a cross-sectional study," BMC Public Health, vol. 18, p. 1396, 2018.

[46] S. Park and Y. Kim, "Prevalence, correlates, and associated psychological problems of substance use in Korean adolescents," BMC Public Health, vol. 16, p. 79, 2016.

[47] G. Buruh, S. Berhe, and M. Kassa, "Prevalence and determinants of substance abuse among street children in Mekelle city, Tigray, Ethiopia: crossectional study," PharmaBitika, vol. 1, no. 1, pp. 82-93, 2014.

[48] A. O. Olumide, A. C. Robinson, P. A. Levy et al., "Predictors of substance use among vulnerable adolescents in five cities: findings from the Well-being of Adolescents in Vulnerable Environments study," J Adolesc Health, 2014.

[49] A. Gizaw, D. Jara, and K. Ketema, "Risky sexual practice and associated factors among high school adolescent in Addis
Ababa, Ethiopia, 2014," Family Medicine \& Medical Science Research, vol. 3, p. 141, 2014.

[50] T. Habesha, Z. Aderaw, and S. Lakew, "Assessment of exposure to sexually explicit materials and factors associated with exposure among preparatory school youths in Hawassa City, Southern Ethiopia: a cross-sectional institution based survey," Reproductive Health, vol. 12, p. 86, 2015.

[51] D. T. L. Shek and C. M. S. Ma, "Consumption of pornographic materials among Hong Kong early adolescents: a replication," The Scientific World Journal, vol. 2012, 2012.

[52] A. Ketema, "Assessment of exposure to sexually explicit materials, effects on early sexual initiation and other risky sexual behaviours among preparatory school students in Addis Ababa, Ethiopia," Unpublished thesis, AAU, 2016.

[53] L. Berhanu, "Assessment of exposure to sexually explicit materials and other factors as predictors of sexual activity among in-school youth in Addis Ababa," Unpublished MSc thesis AAU, 2008.

[54] J. Peter and M. Patti, "Valkenburg adolescents' exposure to sexually explicit internet material, sexual uncertainty, and attitudes toward uncommitted sexual exploration. Is there a Link?" Communication Research, vol. 35, no. 5, pp. 579-601, 2008.

[55] A. D. Dwulit and P. Rzymski, "The potential associations of pornography use with sexual dysfunctions: an integrative literature review of Observational studies," Journal of Clinical Medicine, vol. 8, p. 914, 2019.

[56] Marie-Therese Luder, I. Pittet, A. Berchtold, C. Akre, P.-A. Michaud, and J.-C. Surı, "Associations between online pornography and sexual behavior among adolescents: myth or reality?" Archives of Sexual Behavior, vol. 40, pp. 1027-1035, 2011. 